\title{
PENGARUH PENGETAHUAN, KEPEDULIAN DAN SIKAP PADA LINGKUNGAN TERHADAP MINAT PEMBELIAN PRODUK HIJAU
}

\author{
Ristianawati Dwi Utami \\ Tri Gunarsih \\ Triana Aryanti \\ Universitas Teknologi Yogyakarta
}

\begin{abstract}
The main issues of this study is how cognitive and affective factors influence green products purchase. The objectives of this study are: (1) examine the influence of environmental knowledge on green purchase intention based on gender differences as a moderating variable, (2) examine the influence of environmental concerns on on green purchase intention based on gender differences as a moderating variable, (3) examine the influence of attitude on green purchase intention based on gender differences as a moderating variable, (4) examine the influence of gender on green purchase intentions. Results of this study are (1) environmental knowledge does not significantly influence green purchasing intention when moderated by gender with $p_{\text {value }}(0.560)>0.05$, (2) environmental concern does not significantly influence green purchase intentions when moderated by gender with $p_{\text {value }}(0.475)>0.05$, (3) green purchase attitude are not significantly influence green purchase intentions when moderated by gender with $p_{\text {value }}$ $(0.781)>0.05$, (4) gender diferences are not influence green purchase behavior with $p_{\text {value }}(0.628)>0.05$. These results contrast with previous findings Tikka (2000) who explains that men are more likely to have more envormental knowledge compared with woman. The findings also do not support research cby Mohai (1992) and Stern (1992) who found that women are more concerned about the environment than men and Mustafa (2007) which states that women express greater environmental concern than men. But research is supported by the findings of Chen and Chai (2010) that there is no difference between the attitude of male students and female students on the environment and green products.
\end{abstract}

Keyword: enviromental knowledge, enviromental concern, green purchase intentions, gender diferences.

\section{PENDAHULUAN}

Kerusakan lingkungan, kelangkaan bahan mentah dan energi serta peningkatan polusi sudah menjadi masalah global. Hal ini menuntut masyarakat untuk meningkatkan kepedulian terhadap lingkungan. Dalam dunia bisnis, munculnya environmentalism corporate merupakan bentuk kepedulian terhadap lingkungan yang dihadapi oleh perusahaan dan upaya untuk mengintegrasikan permasalahan lingkungan hidup dalam rencana strategis perusahaan. Bentuk kepedulian perusahaan terhadap lingkungan hidup juga ditunjukkan dengan melakukan praktik pemasaran hijau (green marketing). Manfaat pemasaran hijau bagi perusahaan ialah memperoleh citra yang positif dari tanggung jawab memproduksi sebuah produk yang ramah lingkungan. Sedangkan 
manfaat pemasaran hijau bagi konsumen ialah mendapatkan produk yang berkualitas bagi kesehatan maupun bagi lingkungannya. Produk ramah lingkung-an merupakan produk yang dibuat untuk mengantisipasi kerusakan lingkungan yang berkelanjutan, sebagai bentuk inovasi, meskipun memerlukan waktu yang cukup lama untuk disosialisasikan manfaatnya dan diadopsi masyarakat luas. Aktivitas konsumen yang membeli produk ramah lingkungan diistilahkan sebagai green purchase, dimana konsumen bersedia membayar lebih mahal untuk memperoleh produk yang ramah lingkungan karena memper-timbangkan permasalahan lingkungan terhadap produk yang akan digunakan.

Beberapa studi yang dilakukan oleh Ling-Yee (1997), Chan (1999), Vlosky et al. (1999) and Ottman (1995) menemukan bahwa pada konsumen yang berwawasan lingkungan cenderung melakukan kepedulian lingkungan yang kuat, dan konsumen lebih memilih produk-produk yang ramah lingkungan dibandingkan produk yang lain. Konsumen biasanya memiliki kepercayaan (belief) terhadap atribut suatu produk ramah lingkungan, dimana produk tersebut merupakan image yang melekat dalam produk dipilih oleh konsumen. Image produk yang telah menjadi kepercayaan konsumen akan mempengaruhi perilaku (behavior) seorang konsumen untuk melakukan berbagai motif pembelian yang membentuk sikap pada seorang konsumen tersebut. Minat terhadap suatu produk sangat bervariasi pada tiap-tiap individu (Schiffman and Kanuk, 2000). Minat beli seorang konsumen yang berbeda-beda ini terlihat pada konsumen yang beradaptasi pada situasi mempertimbangkan isu lingkungan ketika konsumen melakukan kegiatan pembelian (Laroche et al., 2001).

Menurut Chan (2001) bahwa orientasi seseorang terhadap alam, kolektivisme, pengaruh ekologi, dan pengetahuan tentang ekologi lingkungan berpengaruh terhadap sikap untuk melakukan minat pembelian produk ramah lingkungan. Demikian juga dengan penelitian lain yang dilakukan oleh Mostafa (2007) yang menguji pengaruh perhatian konsumen terhadap ekologi, pengetahuan lingkungan, dan sikap pada perbedaan gender dalam melakukan green purchase. Hasil penelitian yang dilakukan di Mesir ini menunjukkan bahwa perempuan tampaknya kurang menyadari masalah lingkungan dibandingkan dengan lakilaki. Junaedi (2008) meneliti tentang pengaruh gender sebagai pemoderasi pengembangan perilaku konsumen hijau di Indonesia. Penelitian tersebut meneliti hubungan antara nilai konsumen, kognitif, afektif, niat beli, dan perilaku konsumen hijau pada lakilaki dan perempuan. Hasil penelitian mengungkapkan bahwa perempuan berorientasi kepada nilai individualistik berpengaruh pada keinginan untuk membayar produk pangan organik dengan harga premium. Berdasarkan permasalahan yang telah diuraikan, maka studi ini secara umum bertujuan untuk menguji pengaruh pengetahuan lingkungan, kepedulian lingkungan, dan sikap pada pembelian produk hijau terhadap minat pembelian produk hijau dengan perbedaan gender sebagai variabel moderasi.

\section{LANDASAN TEORI DAN PENGEMBANGAN HIPOTESIS}

\section{Green Marketing}

Pemasaran hijau mencakup berbagai aktivitas dalam proses 
produksi, distribusi dan periklanan hingga menawarkan produk hijau yang ramah lingkungan kepada konsumen. Polonsky, Rosenberger, and Ottman (1998) dalam Manongko (2011), mendefinisikan green marketing sebagai konsistensi dari semua aktivitas untuk mendesain pelayanan dan fasilitas bagi kepuasan kebutuhan dan keinginan manusia dengan tidak menimbulkan dampak pada lingkungan alam. Mintu (1993) dalam Lozada (2000) mendefinisikan pemasaran hijau (green marketing) sebagai aplikasi dari alat pemasaran untuk memfasilitasi perubahan yang memberikan kepuasan organisasi dan tujuan individual dalam melakukan pemeliharaan, perlindungan, dan konservasi pada lingkungan fisik. Sedangkan Ottman et.,al (2006), mengemukaan bahwa dimensi green marketing, dengan mengintegrasikan lingkungan ke dalam semua aspek pemasaran pengembangan produk hijau (green product) dan komunikasi (green communication).

\section{Green Purchase}

Menurut Min dan Galle (1997), green purchase dapat meningkatkan posisi ekonomi sebuah perusahaan dengan pengurangan pengeluaran biaya perusahaan, konservasi atau pencegahan terhadap kerusakan sumber daya alam di sekitarnya yang akan menaikan citra perusahaan tersebut. Harga produk hijau di pasaran dijual relatif lebih mahal, sehingga secara umum dapat memberikan profit yang lebih bagi perusahaan. Sebagai suatu bentuk kesadaran akan lingkungan yang bebas dari polusi, Chang and Wang (1994) telah mengidentifikasi di beberapa negara berkembang, bahwa $62 \%$ penduduknya menyatakan mereka bersedia membayar dengan harga yang lebih tinggi produk ramah lingkungan dan agar industri lebih baik juga dapat melindungi lingkungan.

\section{Green Product (Produk Hijau)}

Produk hijau (green product) adalah produk yang tidak berbahaya bagi manusia dan lingkungannya, tidak boros sumber daya, tidak menghasilkan sampah berlebihan, dan tidak menyebabkan kekejaman pada ekosistem binatang. Menurut Nugrahadi (2002) dalam Manongko (2011) mengemukakan, produk hijau (green product) adalah suatu produk berwawasan lingkungan yang dibuat oleh pemasar agar ramah terhadap kesehatan dan lingkungan. Suatu produk yang dirancang dan diproses dengan suatu cara untuk mengurangi efek-efek yang dapat mencemari lingkungan, baik dalam produksi, pendistribusian, dan pengkonsumsiannya. Elkington et.,al (1990) dalam Moisander (1996) merumuskan karakteristik dari produk hijau yaitu, tidak membahayakan kesehatan manusia dan hewan, tidak merusak lingkungan pada berbagai tingkat kehidupan, termasuk dalam memproses, penggunaan, dan penjualan, tidak menghabiskan banyak energi dan sumber daya lainnya selama memproses, penggunaan, dan penjualan.

\section{Pengetahuan Lingkungan dan Minat Pembelian Produk Hijau Ber- dasarkan Perbedaan Gender.}

Pengetahuan terhadap lingkungan dapat didefinisikan sebagai sebuah pengetahuan umum tentang fakta, konsep dan hubungan antara lingkungan alam dengan ekosistem di sekitarnya (Fryxell and Lo, 2003). Arcury (1990) dalam Mostafa (2007), berpendapat bahwa gender dapat menjadi faktor penentu dalam besarnya pengetahuan lingkungan yang dimiliki oleh seseorang. Tikka et al. (2003) 
menemukan bahwa pengetahuan lingkungan alam dipengaruhi oleh gender dengan tingkat pengetahuan laki-laki lebih besar dibandingkan perempuan. Sementara itu penelitian yang dilakukan di Mesir oleh Briggs et al. (2003) menemukan bahwa pengetahuan lingkungan perempuan. Penelitian yang dilakukan di Mesir oleh Mostafa (2007) menemukan bahwa laki-laki dengan tingkat penghasilan dan keterlibatan pembelian produk yang tinggi akan secara aktif mencari informasi mengenai produk yang ramah lingkungan. Atas dasar pemikiran tersebut, maka dikembangkan hipotesis sebagi berikut:

H1: Pengetahuan lingkungan berpengaruh positif terhadap minat pembelian produk hijau apabila dimoderasi dengan perbedaan gender.

\section{Kepedulian Lingkungan dan Minat Pembelian Produk Hijau Ber- dasarkan Perbedaan Gender.}

Kepedulian lingkungan secara tradisional dipandang sebagai ukuran konsep mulai dari kepedulian tahap rendah hingga kepedulian tahap tinggi, yang diukur dengan cara pandang lingkungan baru (Milfont dan Duckitt, 2004). Amyx et al., (1994) dalam Junaedi (2005), mendefinisikan kepedulian terhadap lingkungan sebagai suatu derajat pengukuran dimana seseorang dalam mengekspresikan kepeduliannya pada isu-isu lingkungan. Baldassare and Katz (1992), serta Seguin et.al (1998) dalam Mostafa (2007), berpendapat bahwa kepedulian lingkungan memiliki dampak yang signifikansi pada sejauh mana individu termotivasi untuk mengubah perilaku, sehingga mencoba untuk meringankan permasalahan lingkungan hidup. Sedangkan Mohai and Stern (1992) dalam Mostafa (2007) menemukan bahwa perempuan lebih peduli dengan isu-isu lingkungan daripada laki-laki sehingga terdapat perbedaan nilai dan keyakinan antara perempuan dan lakilaki terkait lingkungan. Atas dasar pemikiran tersebut, maka dikembangkan hipotesis sebagi berikut:

$\mathrm{H} 2$ : Kepedulian Lingkungan berpengaruh positif terhadap minat pembelian produk hijau apabila dimoderasikan dengan perbedaan gender

\section{Sikap Pada Pembelian Produk Hijau dan Minat Pembelian Produk Hijau Berdasarkan Perbedaan Gender.}

Penelitian perilaku dalam literatur psikologi menyatakan bahwa sikap merupakan prediktor penting bagi perilaku, minat berperilaku dan merupakan faktor penjelas dari berbagia macam perilaku individu. Sikap seorang konsumen telah digunakan di masa lalu untuk memprediksi konservasi energi dan ekologis kesadaran membeli dan menggunakan suatu produk (Mostafa, 2007). Brown and Haris (1992), menemukan perbedaan antara laki-laki dan perempuan dalam sikap terhadap lingkungan. Chan (2001) menemukan sikap pada pembelian produk hijau antara laki-laki dan perempuan masyarakat Cina tercerminkan dari pengetahuan lingkungan, pengaruh ekologis, dan budaya dalam mengkonsumsi sebuah produk, sehingga sikap pembelian produk hijau antara laki-laki dan perempuan berpengaruh secara signifikan.

Pendapat Allport (1935) dalam Ramdhani (2008), sikap adalah kondisi mental dan neural yang diperoleh dari pengalaman, yang mengarahkan dan secara dinamis mempengaruhi responrespon individu terhadap objek dan situasi yang terkait. Sedangkan menurut Mashadi (2010), sikap merupakan 
penilaian evaluatif konsumen terhadap suatu objek atau produk yang diminati. Atas dasar pemikiran tersebut, maka dikembangkan hipotesis sebagi berikut: H3 : Sikap pada pembelian produk hijau berpengaruh positif terhadap minat pembelian produk hijau apabila dimoderasikan dengan perbedaan gender.

\section{Pengaruh Perbedaan Gender terhadap Minat Pembelian Produk Hijau.}

Gender merupakan pandangan masyarakat tentang perbedaan peran dan tanggung jawab antara laki-laki dan perempuan yang merupakan hasil kontraksi sosial. Perbedaan gender merupakan karakteristik demografi yang menarik untuk diteliti berkaitan dengan isu-isu lingkungan, karena perbedaan peran, keterampilan, dan sikap yang mengarah permasalahan ekologikal. Penelitian yang dilakukan di Singapura oleh Jiuan et., al (2001) dalam Junaedi (2008), menunjukan bahwa peran perempuan dalam kehidupan menyebabkan mereka sadar akan permasalahan lingkungan, sehingga mempengaruhi dalam melakukan minat beli terhadap suatu produk. Pendapat lain oleh LingYee (1997) dalam penelitian Junaedi (2008) menemukan bahwa laki-laki lebih peduli untuk mempertahankan lingkungan sehingga akan lebih memilih produk yang ramah lingkungan.

Hasil penelitian Junaedi (2008) pada konsumen hijau Indonesia, menyatakan baik konsumen laki-laki maupun perempuan memiliki kesamaan dalam minat pembelian produk hijau, kecuali pada konsumen yang berorientasi pada nilai individualistik berpengaruh pada keinginan untuk membayar pangan organik dengan harga premium. Berdasarkan uraian di atas, maka berkaitan dengan perbedaan gender dengan minat beli dapat dirumuskan hipotesis:

H4: Perbedaan gender tidak berpengaruh terhadap minat pembelian produk hijau.

Berdasarkan kajian pustaka dan pengembangan hipotesis, maka model penelitian dapat digambarkan sebagai berikut:

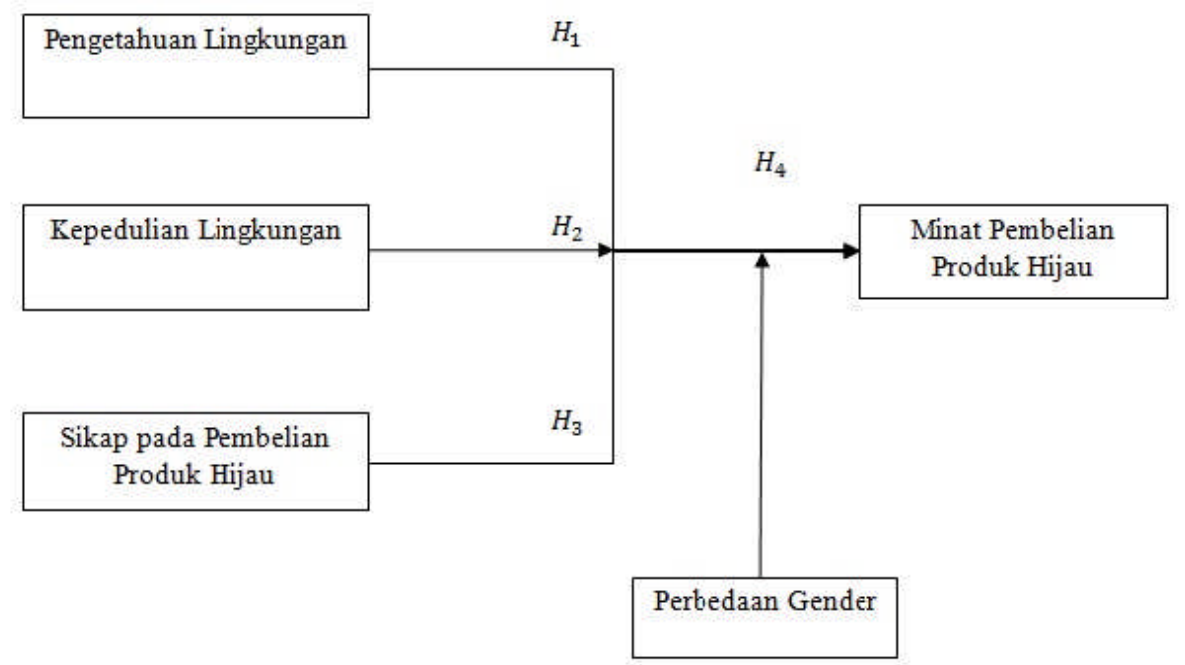

Gambar 1. Model Penelitian 


\section{METODOLOGI PENELITIAN}

\section{Populasi, Sampel dan Jenis Data}

Populasi penelitian ini ialah masyarakat yang mempunyai minat terhadap pembelian produk hijau. Teknik pengambilan sampel yang digunakan ialah convenience sampling, yaitu teknik pengambilan sampel dari elemen populasi (orang atau kejadian) yang datanya mudah diporoleh peneliti. Hal ini dilakukan karena elemen populasi yang dipilih sebagai subyek sampel adalah tidak terbatas sehingga peneliti memiliki kebebasan untuk memilih sampel yang paling cepat dan murah ((Indriantoro, 2009). Sampel dalam penelitian ini ialah mahasiswa Fakultas Bisnis dan Teknologi Informasi di Universitas Teknologi Yogyakarta dan masyarakat Kelurahan $\begin{array}{llllll}\text { Notoprajan } & \text { RT } & 028 & \text { dan } & \text { RT } & 034\end{array}$ Yogyakarta. Adapun ukuran sampel penelitian ini ialah 200 orang. Jenis data yang digunakan ialah data subyek yaitu berupa opini, sikap, pengalaman atau karekteristik seseoran yang menjadi subyek penelitian. Sumber data yang digunakan ialah sumber data primer.

\section{Definisi Operasional Pengetahuan Lingkungan}

Pengetahuan terhadap lingkungan dapat didefinisikan sebagai sebuah pengetahuan lingkungan yang umumnya diketahui, berdasarkan konsep, dan hubungan yang secara alami antara lingkungan dengan ekosistem di sekitarnya. Pengetahuan lingkungan diukur dengan 15 item pernyataan yang dikembangkan oleh Maloney et al., (1998) dalam Mostafa (2007), diukur dengan ialah skala Likert 1-5.

\section{Kepedulian Lingkungan}

Kepedulian lingkungan secara tradisional dipandang sebagai ukuran konsep mulai dari kepedulian tahap rendah hingga kepedulian tahap tinggi, yang diukur dengan cara pandang lingkungan baru (Milfont and Duckitt, 2004). Dunlap dan Van Liere (1978) dalam Mostafa (2007), mengukur kepedulian terhadap lingkungan dengan 15 item pertanyaan.

\section{Sikap Pada Pembelian Produk Hijau}

Sikap terhadap suatu produk ramah lingkungan, yakni bagaimana cara konsumen mengenali produk kemudian konsumen menilai apakah produk tersebut baik dikonsumsi atau tidak, dalam hal kesehatan maupun untuk di lingkungan sekitar. Dengan mengacu pada pendekatan Taylor and Todd (1995) dalam Chan (2001), sikap pada pembelian produk hijau diukur dengan 15 item pernyataan.

\section{Minat Pembelian Produk Hijau}

Minat beli produk ramah lingkungan merupakan keinginan yang timbul ketika konsumen merasa tertarik dan ingin membeli produk yang dilihatnya. Berdasakan instrumen yang dikembangkan oleh Li (1997), Taylor and Todd (1997) dalam Chan (2001), terdapat 15 item pernyataan untuk mengukur minat ataupun niat konsumen untuk terlibat dalam pembelian produk ramah lingkungan.

\section{ANALISIS DATA}

\section{Uji Validitas dan Reliabilitas}

Pengujian validitas instrumen digunakan untuk mengukur sah atau valid tidaknya suatu kuesioner (Ghozali, 2011). Uji validitas menggunakan Confirmatory Factor Analysis (CFA) dimana setiap item pernyataan harus memiliki factor loading lebih dari 0,60 dan $\mathrm{r}$ kritis $>0,3$. Hasil uji validitas menunjukkan bahwa seluruh item 
perertanyaan dalam instrument penelitian ialah valid. Pengujian reliabili- tas merupakan pengujian kehandalan dan kekonsistenan instrument penelitian

Tabel 1. Hasil Uji Reliabilitas Instrumen

\begin{tabular}{l|c|c|c}
\hline \multicolumn{1}{c|}{ Instrumen } & $\begin{array}{c}\text { Alpha- } \\
\text { Cronbach }\end{array}$ & Cut off & Keterangan \\
\hline Pengetahuan lingkungan & 0.698 & 0,60 & Reliabel \\
$\begin{array}{l}\text { Kepedulian lingkungan } \\
\text { Sikap pada pembelian } \\
\text { produk hijau }\end{array}$ & 0.802 & 0,60 & Reliabel \\
$\begin{array}{l}\text { Minat pada pembelian } \\
\text { produk hijau }\end{array}$ & 0.788 & 0,60 & Reliabel \\
\hline
\end{tabular}

diukur dengan nilai koesfisien Cronsbach's Alpha lebih besar dari 0,6 (Sekaran, 2006). Hasil uji reliabilitas instrumen dengan metode AlphaCronbach disajikan dalam tabel 1 diatas.

\section{Analisis Regresi (Uji Interaksi)}

Analisis ini dilakukan untuk mengetahui apakah variabel pengetahuan lingkungan, kepedulian lingkungan, dan sikap pada pembelian produk hijau berpengaruh terhadap minat pembelian produk hijau apabila dimoderasikan dengan perbedaan gender. Hasil pengujian menggunakan moderated regresion analysis dapat dilihat pada tabel 2.

Berdasarkan tabel 2, tampak bahwa secara simultan Pengetahuan Lingkungan, Kepedulian Lingkungan dan Sikap pada Pembelian Produk Hijau berpengaruh positif dan signifikan terhadap Minat Pembelian Produk Hijau dengan $\mathrm{P}_{\text {value }}$ masing-masing 0,03 ; 0,066 dan 0,000. Sedangkan perbedaan gender tidak berpengaruh terhadap Minat Pembelian Produk Hijau dengan Pvalue 0,547>0,05.

Tabel 2. Hasil Uji Regresi Berganda Linear

Persamaan Satu

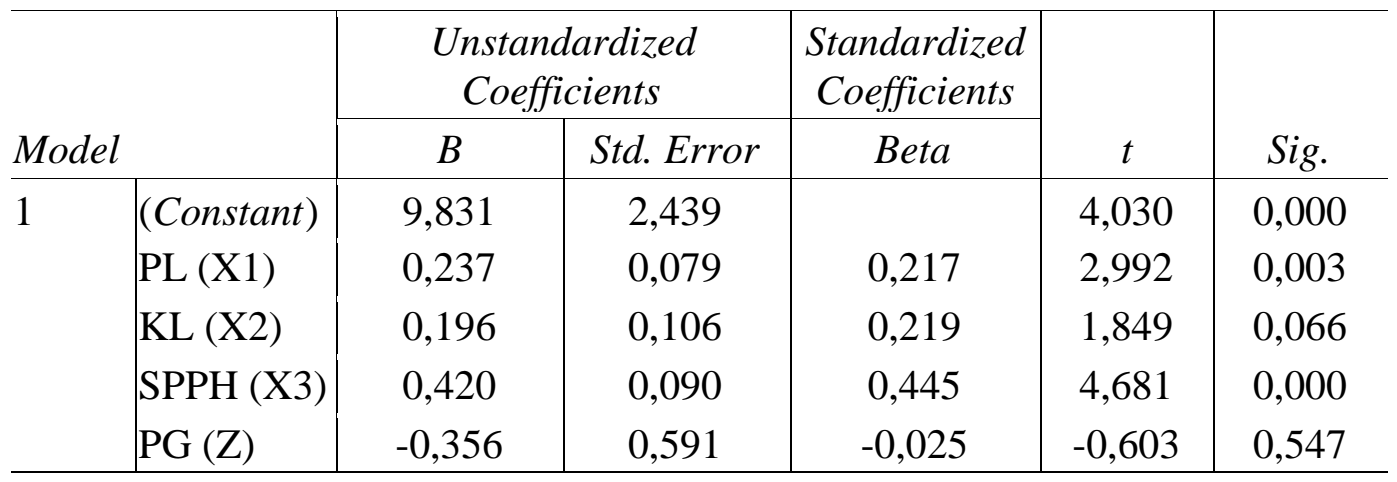

a. Dependent Variable: $\mathrm{MPPH}(\mathrm{Y})$

$R^{2}=0,679 \quad \mathrm{~F}=103,100 \quad \mathrm{Sig}=0,000$ 
Tabel 3. Hasil Regresi Berganda Linear (Uji Interaksi)

Persamaan Dua

\begin{tabular}{|c|c|c|c|c|c|c|}
\hline \multirow{2}{*}{\multicolumn{2}{|c|}{ Model }} & \multicolumn{2}{|c|}{$\begin{array}{c}\text { Unstandardized } \\
\text { Coefficients }\end{array}$} & \multirow{2}{*}{$\begin{array}{c}\begin{array}{c}\text { Standardized } \\
\text { Coefficients }\end{array} \\
\text { Beta } \\
\end{array}$} & \multirow[b]{2}{*}{$t$} & \multirow[b]{2}{*}{ Sig. } \\
\hline & & $B$ & Std. Error & & & \\
\hline \multirow[t]{8}{*}{1} & (Constant) & 10,118 & 2,768 & & 3,655 & 0,000 \\
\hline & PL (X1) & 0,341 & 0,203 & 0,312 & 1,683 & 0,094 \\
\hline & KL (X2) & $-0,005$ & 0,316 & $-0,005$ & $-0,015$ & 0,988 \\
\hline & SPPH (X3) & 0,491 & 0,268 & 0,520 & 1,833 & 0,068 \\
\hline & MPPH (Z) & $-0,929$ & 1,911 & $-0,065$ & $-0,486$ & 0,628 \\
\hline & PL*PG (Moderat1) & $-0,082$ & 0,141 & $-0,326$ & $-0,585$ & 0,560 \\
\hline & KL*PG (Moderat2) & 0,147 & 0,205 & 0,578 & 0,715 & 0,475 \\
\hline & \begin{tabular}{|l} 
SPPH*PG \\
(Moderat3)
\end{tabular} & $-0,046$ & 0,167 & $-0,187$ & $-0,278$ & 0,781 \\
\hline
\end{tabular}

a. Dependent Variable: Y

$\mathrm{R}^{2}=0,680 \mathrm{~F}=58,339 \mathrm{Sig}=0,000$

Berdasarkan tabel 3, hasil uji interaksi antara varibel independen dengan Perbedaan Gender, terlihat bahwa (1) pengetahuan lingkungan tidak berpengaruh secara signifikan terhadap minat pembelian produk hijau apabila dimoderasi oleh gender dengan $\mathrm{P}_{\text {value }}(0,560)>0,05$; (2) kepedulian lingkungan tidak berpengaruh secara signifikan terhadap minat pembelian produk hijau apabila dimoderasi oleh gender dengan $\mathrm{P}_{\text {value }}(0,475)>0.05$; (3) sikap pada pembelian produk hijau tidak berpengaruh secara signifikan terhadap minat pembelian produk hijau apabila dimoderasi oleh gender dengan $\mathrm{P}_{\text {value }}$ $(0,781)>0.05$; (4) gender tidak berpengaruh terhadap minat pembelian produk hijau dengan $\mathrm{P}_{\text {value }}(0,628)>0,05$.

\section{HASIL DAN PEMBAHASAN}

Hasil penelitian menunjukkan bahwa hipotesis 1 tidak terbukti, dimana pengetahuan lingkungan tidak ber- pengaruh terhadap minat pembelian produk hijau apabila dimoderasi oleh perbedaan gender. Temuan ini tidak konsisten dengan penelitian Mostafa (2007), yang menemukan bahwa pengetahuan lingkungan memiliki pengaruh yang signifikan terhadap minat pembelian produk hijau dengan perbedaan gender. Penelitian ini juga berbeda dengan temuan Tikka et al. (2000) yang menemukan bahwa pengetahuan lingkungan alam dipengaruhi oleh gender dengan tingkat pengetahuan laki-laki lebih besar dibandingkan perempuan. Hasil lain dari penelitian ini ialah bahwa kepedulian lingkungan tidak berpengaruh terhadap minat pembelian produk hijau apabila dimoderasi oleh perbedaan gender, sehingga hipotesis 2 tidak terbukti. Temuan ini berbeda dengan penelitian Mostafa (2007), yang menemukan bahwa perempuan lebih mengekspresikan kepedulian lingkung- 
an yang lebih tinggi dibandingkan lakilaki.

Hipotesis 3 tidak terbukti, dimana sikap terhadap pembelian produk hijau tidak berpengaruh terhadap minat pembelian dengan apabila dimoderasi oleh perbedaan gender. Hasi penelitian ini berbeda dengan penelitian Chan (2001) yang menyatakan bahwa sikap pada pembelian produk hijau berpengaruh terhadap minat pembelian produk hijau. Namun temuan ini didukung oleh penelitian Chen and Chai (2010) yang menunjukan bahwa tidak terdapat perbedaan antara siswa laki-laki dan siswa perempuan dalam sikap terhadap lingkungan dan sikap mereka terhadap produk hijau. Perbedaan gender tidak berpengaruh terhadap minat pembelian produk hijau, sehingga hipotesis 4 terbukti. Hasil penelitian ini konsisten dengan penelitian Junaedi (2008), bahwa baik laki-laki maupun perempuan memiliki kesamaan dalam melakukan minat pembelian produk hijau.

\section{SIMPULAN}

Dari hasil analisis dan pembahasan dapat disimpulkan bahwa secara simultan pengetahuan lingkungan, kepedulian lingkungan dan sikap terhadap produk hijau tidak berpengaruh terhadap minat pembelian produk hijau apabila dimoderasi oleh perbedaan gender. Sehingga dengan kata lain tidak terdapat perbedaan pengetahuan lingkungan, kepedulian lingkungan dan sikap terhadap produk hijau antara perempuan maupun lakilaki dalam minat pembelian produk hijau.

Keterbataan penelitian ralah
pertama, bahwa variabel diukur
berdasarkan pada pernyataan pribadi
tentang perilaku di masa lalu atau
prediksi perilaku di masa yang akan

datang sehingga bisa menimbulkan bias. Penelitian kedepan diharapkan menggunakan metode wawancara dalam pengumpulan data, kerena banyak reponden yang tidak familiar dengan produk hijau sehingga kuesioner diisi secara asal-asalan sehingga bisa mengurangi tingkat bias. Kedua, penelitian ini menggunakan pendekatan crosss-sectional daripada pendekatan longitudinal untuk mencari data. Sehingga lebih fokus pada pengamatan perilaku sesaat daripada pengamatan perubahan perilaku. Penelitian kedepan diharapkan dapat menggunakan pendekatan longitudinal untuk melihat perubahan perilaku dari waktu ke waktu.

\section{DAFTAR PUSTAKA}

Briggs, J., Sharp, J., Hamed, N \& Yacoub, H. 2003. Changing women's roles, changing enviromental knowledge: evidance from Upper Egypt, The Geographical Jurnal, 169, 313325

Brown, G. dan C. Harris. 1992. The US forest service: toward the new resource management paradigm?. Society and Natural Resources, 5, 231-245.

Chan, Ricky Y.K. 1999. Environmental Attitudes and Behaviour of Consumer in China. Journal of International Consumer Marketing, 11:4, p. 25-52.

Chan, Ricky Y.K. 2001. Determinants of Chinese Consumers' Green Purchase Behavior. Journal Psychology \& Marketing, Vol. 8, No. 4, April, pp. 389-413. 
Chang, Chun, and Yijiang Wang.1994.The Nature of the Township and Village Enterprise, Journal of Comparative Economics. 19, pp. 434-452.

Fryxell, G, \& Lo, C. 2003. The influence of enviromental knowledge and values on managerial bahaviors on behalf on the enviroment: an emprirical examination of managers in China. Journal of Business Ethics, 46, 45-59

Ghozali, Imam, 2011, Aplikasi Analisis Multivariate Dengan Program IBM SPSS 19, Edisi 5, Universitas Diponegoro, Semarang.

Indriantoro, Nur, dan B. Supomo, 1999, Metodologi Penelitian BisnisUntuk Akuntansi dan Manajemen, Edisi Pertama, BPFE-Yogyakarta.

Junaedi, M.F. Shellyana, 2005, Pengaruh Kesadaran Lingkungan pada Niat Beli Produk Hijau: Studi Perilaku Konsumen Berwawasan Lingkungan, Benefit Jurnal Manajemen dan Bisnis, Vol. 9, No. 2, hal. 189-201.

Junaedi, M.F. Shellyana. 2008. Pengaruh Gender Sebagai Pemoderasi Pengembangan Model Perilaku Konsumen Hijau Di Indonesia. Kinerja Jurnal Bisnis dan Ekonomi. Vol. 12, No. 1, Hal 17-37

Laroche, Michel, Jasmin Bergeron, dan Guido Barbaro-Forleo. 2001.
Targeting Consumers Who are Willing to Pay More for Environmentally Friendly Products. Journal of Consumer Marketing, Vol. 18, No. 6, pp. 503-520.

Ling-yee, Li,. 1997. Effect of collectivist orientation and ecological attitude on actual environmental commitment: The moderating role of consumer demographics and product involvement. Journal of International Consumer Marketing, Vol. 9 No. 4, pp. 3153.

Lozada, H.R. 2000. Ecological Sustainability and Marketing Strategy : Review and Implication, Seton Hall University.

Manongko, Allen A. CH., 2011, Green Marketing dan Pengaruhnya Terhadap Keputusan Pembelian Melalui Minat Membeli Produk Organik: Studi Pada Pelanggan Produk Organik Di Kota Manado,Publikasi Ilmiah, Universitas Brawijaya, Malang.

Mashadi, 2010, Pengaruh Motivasi, Persepsi,Sikap dan Pembelajaran Konsumen Terhadap Keputusan Pembelian Minumkan Kemasan Merek "Teh Botol Sosro" Di Kawasan Depok, Universitas Gunadarma.

Milfont, T. L., dan J. Duckitt, 2004, The structure of environmental attitudes: First- and second-order confirmatory factor analysis, Journal of Environmental Psychology, 24, 289-303. 
Min, H., dan Galle, W., 1997, Green purchasing strategies: trends and implications, International Journal of Purchasing and Materials Management 33 (3).

Moisander, J., 1996, Motivation for Ecologically Oriented Consumer Behaviour, www.lancs.ac.uk. Diakses tanggal 25 Maret 2012.

Mostafa, Mohamed M. 2007. Gender Differences in Egyptian Consumers' Green Purchase Behaviour, The Effect Environmental Knowledge, Concern, and Attitude. International Journal of Consumer Studies 31 (2007), 202-229.

Ottman, Jacquelyn,. 1995. Today's consumers turning lean and green. Marketing News, Vol. 29, Iss. 23, pp. $12-14$.

Ottman, J., Stafford, E, Hartman, C. 2006. Avoiding Green Marketing Myopia. Environment, 48(5), 22-36.

Ramdhani, Neila, 2008, Sikap dan Beberapa Definisi Untuk Memahaminya, http://neila.staff.ugm.ac.id/word press/wpcontent/uploads/2008/03/definisi .pdf, Diakses tanggal 6 juni 2012.

Schiffman, Leon G., dan Leslie Lazar Kanuk. 2000. Consumer Behavior. 7th ed., Prentice Hall: International.
Schiffman, L.G and L. L. Kanuk, 2007. Perilaku Konsumen, Edisi 7, Penerbit PT Indeks, Jakarta.

Sekaran, U. 2006, Research Methods for Business, John Willay and Son, Inc, New York

Tikka, P., Kuitunen, M. \& Tynys, S,. 2002. Effect of educational background on students attitudes, activity levels, and knowledge concerning the environment. Journal of Enviromental Education, 31, 1219. 